\title{
Chapter 4 \\ Mapping an Emerging New Economic Paradigm in Practice
}

\begin{abstract}
Recognizing the importance of mind-sets in the sustainability transition allows an opportunity to reflect and examine underlying assumptions, identify shared values and cultivate common ground. Each of these contributes to defining the shared goals and the compelling visions necessary to bring these changes about.
\end{abstract}

UNEP, GEO-5 (2012: 422).

Driving the system to do more will not be enough if something different is needed. When the goals and ends of the system are in question, then systems innovation has to focus not merely on new means but on a new purpose.

Leadbeater and Mulgan, Systems Innovation (2013: 46).

Vision is not enough; it must be combined with venture. It is not enough to stare up the steps, we must step up the stairs.

Vaclav Havel

Transformation research is close to innovation research and practice in its emphasis on experimentation and the role that pioneers play when it comes to testing new solutions. Many corporations have similar prototype programs or cross-finance one unit to explore different practices. In recent years in particular, this has also been about making things more sustainably. But no corporation manages to make sustainable production the core benchmark of their business model. Instead, most of the 1000 Global Compact CEOs interviewed by Accenture in 2013 have lamented that sustainability is "not bankable." The Global Compact is a UN initiative that was launched by Kofi Annan as Secretary General with the goal of improving reporting by big corporations on their contributions to sustainable development and human rights. Unlike 2009 respondents, during the first round of interviews many of the CEOs of participating corporations were 'frustrated' that market, investment and reporting structures made the business case for sustainability nearly impossible. Without state regulation, the company bosses stated, they could not get out of what they called "pilot paralysis," in which some small-scale individual projects or units become champions for sustainability but can never scale up. Business therefore seems to have reached its "plateau in advancing sustainability" before "radical, structural change of markets and systems" make further reaching reorientations of investments and restructuration of value chains possible (Accenture 2013: 5). 
Structurally it is true that today's market regulations, investment and productivity standards lead to a competitive advantage for those externalizing their social and environmental costs. In Brussels I was part of the civil society community that had to remind the corporate representatives on the discussion panels that writing glossy reports and transferring the responsibility for change onto governments was not going to lead to substantial legal changes unless they told their lobbyists to support rather than block such a policy framework. Meanwhile, firms that put sustainable solutions at the core of their business models were hardly ever represented. Since they face tough price and access competitions with firms that externalize a lot of the social and environmental costs, they often do not have profits to spare for remunerating lobbyists.

Transformation research thus clearly differentiates between 'incumbents,' those parties, firms or organizations prominently embedded in the working of the given regime structure, and 'pioneers' whose solutions challenge this default and thus have the irritating effect that can lead to transformative dynamics. Of course there are also agents or subgroups within regime structurations that push for sustainability innovations on that level (e.g., the sustainably run units). Yet, their regime level is more likely an internal one: if their innovations were politically supported their motherships' business models would be disrupted.

So this chapter shines a light on some pioneering initiatives that were radical enough to put recoupling productive processes with human well-being and nature's laws at the core of their practice. Intending to check which development paradigms galvanize enough energy and support for collective transformative strategies in line with the wider SDG ambitions, I chose examples that fulfill the following criteria:

- Economic growth or growing profits may be an element in the business plan but certainly not an overruling one. Instead, the optimal rate of economic growth depends on the role it plays in fulfilling the overarching purpose of supporting human well-being and respecting nature's reproductive cycles. This subscribes to the embedded-systems-view captured in Fig. 3.4 and implies that economic processes are means to higher ends. If those can be met by a steady state or shrunk economy or turnover that is fine, too.

- In order for the recoupling purpose to inform the incremental actions and changes necessary to innovate their systems, each of the examples has developed a set of principles, symbols, indicators and measures to track changes. These are not kept within separate sustainability departments but inform the core decision-making bodies and strategies. They are communicated widely and explicitly and underpin the narratives with which reliability of expectation and foundations for cooperation are being built.

- Since single pioneering examples will not lead to transformations unless their existence and support causes sufficient irritation to overarching regime structurations, I have chosen four examples with the characteristics of a movement. The definition of values, purpose, goals, indicators, and measures within these examples is done with a degree of transparency and openness that allows others to learn, replicate and feed back. This can develop into a community of practice 
(a group in itself). By sharing best practice, experiences in implementation and also difficulties, this community of practice can also identify common political interests and start advocating and acting jointly for overarching system change (a group for itself). The latter can also be done and supported by people who are not directly part of the pioneering practice but share their purpose and worldview and would like such solutions to spread.

- I also found it intriguing to check for similarities across sectors and, due to language barriers, found that easier than a proper cross-cultural assessment of, say, multiple business networks. I am aware that this has led to a set of examples that is both somewhat eurocentric and confined to those with a good internet presence, which made them easier to research.

This is how the Economy for the Common Good (a prominent business initiative in Germany and Austria), Transition Towns (an urban community initiative born in the United Kingdom), and the Commoning movement (a civil society initiative spanning the Atlantic between the United States and Europe) were chosen. Only in the context of government initiatives around 'Beyond GDP' was I lucky enough to visit the pioneering nation of Bhutan, whose Gross National Happiness or GNH framework is referenced by many.

In the Multilevel-Perspective on societal change presented in Fig. 2.1, the first three examples of Economy of the Common Good businesses, Transition Towns and Commoning initiatives would count as pioneers at the niche level. The last example of a national government strategy, the GNH Framework of Bhutan and its policy commission, would be a pioneer at the regime level, leading change from within the overarching structurations.

Of course such a short summary in a book has to be very selective. It cannot do justice to a proper summary of what exactly is happening in each initiative. So the most important focal point for the exploration has been the identification of some crucial paradigmatic differences to the mainstream concepts I presented in Chap. 3. I was surprised by the degree of commonality between the four cases in this.

I have summarized their radically new purpose as one of recoupling economic processes with human well-being and nature's reproductive laws. Since all of them confront strong path dependencies in the overarching and surrounding systemsand also partly in their own-their incremental change strategies are ones of successive double-decoupling:

1. Decouple the production of goods and services from unsustainable, wasteful or uncaring treatment of humans, nature and animals (do better).

2. Decouple the satisfaction of human needs from the imperative to deliver ever more economic output (do well).

The summary details core findings in juxtaposition to the mainstream economic development paradigm.

Another shortcoming of any desktop assessment in comparison to proper field research is the degree of informed critical discussion that is possible. Here, it is limited to a recapitulation of the most prominent critical voices found on the web. 
Most of these address more the implementation processes than the conceptual frameworks. A lot of the criticism I found could be applied to any given plan or agreement for collective action: a proposal still allows for abuse, and some concrete actions taken by members of the network will not live up to its declared values and principles.

While it is important to highlight instances where thinking or declared purpose deviate from doing or lived purpose, the locus of responsibility for this does not necessarily lie with the founders of a movement. They cannot and arguably should not seek to prescribe how exactly people engage in putting the joint vision and goals into practice. The SDGs themselves are actually a great example for this: whilst almost all governments accepted the goals and targets and indicators, they were not made into binding commitments. Monitoring and reporting on progress is voluntary and each country is going to prioritize meeting some goals over meeting others. The idea is that peer reviewing will inspire commitment and mutual learning between countries with similar challenges.

So hardly any pioneer or UN body can ensure that everyone using their ideas or claiming to serve the SDGs will do so in the way that was originally envisioned or intended. This is an unavoidable characteristic of movements and politics, and none of the critiques I came across included a proposal on how, in real concrete practical terms, the formation of movements and government of cooperation could feasibly resolve these issues.

Others took an oppositional stance, believing that a progressive and inclusive movement could not prescribe such detailed rules and benchmarks. Here I would counter that without some agreement as to what this group of people stands for and what it does not represent, it will never become a political force that can jointly work for change. So in the end it will be the integrity, clarity, and courage of the people involved that influences how individual freedom and collective action are combined and thus how progressive it is. Thus, in each example I briefly pick up on what I felt were the most common reproaches, but can only draw superficial conclusions. An empirically sound assessment was not possible but would be a great project for which to seek funding. In reaching my conclusions, I found that the most important characteristic of these examples was their willingness to reflect criticism and to assess how the incremental steps taken could continue to support the radically different purpose that generated each initiative.

\subsection{Pioneering Businesses: Common Good Matrix and Balance Sheets}

The concept of Corporate Social Responsibility came into existence as a consequence of acknowledging the important role of business in shaping development. Business was to take into consideration the wider setting in which it operated, and to focus on more than simply making a profit. The approach of 'triple bottom line' 
reporting refers to an extension of the accounting standards of businesses that also includes information on the environmental and social impacts of their activities.

Several standards have been developed for this and some, like the Global Reporting Initiative, have become widely influential reference frameworks. Campaigns have been launched to make the entire approach obligatory and comprehensive, rather than a voluntary and selective endeavor. These campaigns have also sought transparency on lobbying behavior and a higher degree of accountability, which should involve sanctions for corporations violating certain standards.

None of these initiatives, however, have gone as far as to address the general purpose of corporations and business in society. Triple bottom line accounting is about slowly reducing so-called externalities - social and environmental costs - in the process of making profits. This is different from the 2009 initiative on the Economy for the Common Good or Gemeinwohlökonomie. It starts from the system view that the overall challenge of societies of thinking and aspiring individuals is to find a balance between community responsibility and individual freedom. Neither functions without the other. Individuals need to cooperate to flourish and build wealth, and the community needs creative deviators in order to keep on diversifying and adapting.

Some of the uninformed criticism of the Common Good Economy rejects the 'communist' ideology behind it. But Christian Felber, the leading proponent of this movement, sees the path toward sustainability as lying in reconnecting private entrepreneurship with the overall goal of the common good. Common good as an output goal can only be defined in democratic political processes, and private entrepreneurship can, if a business is run correctly, contribute to that common good. We see that the definition and possible redefinition of ends to which an economy should contribute are put center stage. This is unlike the mainstream economic view in which 'more growth' is the single abstract pole star.

The website ecogood.org chronicles some historical references to the common good as an overarching goal for societal development and also puts forward 20 principles or ideas for what putting that into practice could look like. None of these are seen as fixed rules but are meant to inspire reflection and dialogue on the values, norms and practices that status quo solutions nurture or even prescribe.

With this starting point, status quo solutions are judged to incentivize egoism, greed and striving for power, and to reward those who behave most effectively toward egotistical, greedy or power-hungry ends. What are called 'competition rules' have lost almost all of the com, the Latin word for 'together' or 'we.' They are all about 'I' and ensure that winners take pretty much all, while making even hostile takeovers of entirely healthy businesses feasible. The result is a constant incentive for asocial behavior and a structural driver of the concentration of wealth and power, because successful, attacking units are better prepared for the next round of what should be called 'contrapetition.'

The goal of the movement and the 20 proposed principles are thus "more intelligent rules of the game." The first expresses the overall mission purpose: 
The same collectively shared values that contribute to fulfilling interpersonal relationships are the basis for the Economy for the Common Good: confidence building, cooperation, appreciation, democracy, solidarity. Scientific research proves that fulfilling interpersonal relationships constitute a key factor to happiness and motivation (Economy for the Common Good 2010a).

Following from this are the basic paradigmatic changes that lead away from contrapetition to cooperation, from profit to common good output, and from market control to democratic decision-making. This is not to be confused with the socialist centrally planned state that Felber believes suffocated individual freedom. It is also not about prohibiting asocial business conduct but simply stopping the incentivization of it and making it instead the more difficult solution under an altered institutional framework. Thus the overall idea is to change the default setting so that unsustainable behavior, like the externalization of social and environmental costs, is no longer a competitive advantage. Behavioral economics is full of such ideas and has coined the term 'nudging' for non-regulatory interventions in which the architecture of choice makes sustainable behavior easier rather than harder. Supporting evidence on the anti-sustainability impact of the current default has been delivered by the Global Compact—Accenture CEO Study on Sustainability cited above.

Changing accounting rules to internalize environmental and social costs thus seems to be an obvious leverage point that would allow plenty of disruptive innovations to drive 'dirty' competitors out of markets while at the same time incentivizing efficiency technology breakthroughs. However, the question remains: can endless exchange value competition for private profit remain as the overarching goal of business and lead to sustainable systems? The answer given by the Economy for the Common Good movement is clearly negative and their prototype for new balance sheets is far more encompassing. As principle 3 states, "economic success will no longer be measured with (monetary) exchange value indicators, but with (non-monetary) use value indicators" (Economy for the Common Good 2010a).

As a consequence, similar indicators for business and societal performance can align bottom-up and top-down initiatives toward the new purpose on which economies should deliver:

On the macroeconomic level (national economy) the Gross Domestic Product (GDP) will be replaced - as an indicator of success - by the Common Good Product. On the microeconomic level (company) the financial balance sheet will be replaced by the Common Good Balance Sheet (CGBS). The CGBS becomes the main balance sheet of all companies. The more companies act and organize themselves along social, ecological and democratic lines, the more solidarity they display, the better will be the results of their Common Good Balance Sheet. The better the CGBS results of the companies within a national economy, the higher its Common Good Product (Economy for the Common Good 2010a).

The genesis of this movement came from 70 businesses that started reporting with the first CGBS in 2010. By mid-2015 the number of companies had risen to 1811 , in addition to 232 clubs, six communes or regions and over 6000 individual supporters. An interactive map of the network can be found on the website www. ecogood.org. The initial experiences of the pioneers has led to slight modifications 
to the matrix of indicators and the current version (4.1) has five different categories and five stakeholder groups for whom principles are formulated. The categories are human dignity, solidarity, ecological sustainability, social justice, and democratic co-decision-making and transparency. The stakeholder groups are suppliers, creditors, employees including co-owners, customers/partners/service providers and the societal environment. Each matrix field has a short description of the type of conduct that is expected and also gives a point score that expresses the weighting of this principle in the overall set.

The rather unusual final row in the matrix is one with negative criteria, for which points have to be subtracted. These are primarily about violations of standards and principles that have been agreed by the international community, for example, in OECD, International Labour Organization (ILO) or UN guidelines. These include human rights, worker protection, environmental standards, tax avoidance, non-disclosure on subsidiaries, non-disclosure of payments to lobbyists, the prohibition of work councils and dumping prices. They also contain strong normative judgments about what are considered to be inhumane products such as land mines, genetically modified organisms, nuclear weapons and nuclear waste, plus unequal pay for men and women, equity yield rates over $10 \%$, excessive income inequality within a business or blocking patents and hostile takeovers.

The negative points that companies can 'earn' in this category are much higher than the positive ones that can be gained through common good activities. This sends a strong signal that the violation of agreements and the intentional undermining of standard practices are worse for cohesion, trust and relationships than not actively pushing up the benchmarks (Economy for the Common Good 2010b).

While the matrix calculates a final number that can be compared with others, the entire concept of it lies much more in stimulating a structured conversation and process within the business about its shortcomings and any room for possible improvements. Peer learning lies at the center of the concept and businesses decide themselves if they want to hire one of the growing network of balance sheet consultants. It is also up to them to add an external audit or not. The mid-term political goal, however, is to make CGBS reporting mandatory and, in a first step, to guarantee tax breaks or public procurement advantages for those participating or faring really well.

The initiative also encourages the surrounding community, as well as the local government, to support these businesses with customer loyalty, public acknowledgement or even to undertake their own evaluation. These are called 'Common Good Regions' and 45 of them have been launched in Austria, Germany, Switzerland, Italy, Spain, Portugal, Greece, Great Britain, the United States and recently also in South America.

In northern Italy and Austria in particular, mayors and communes are now coming together to develop visions for more regionalized, value-based, participatory and sustainable supply chains and to see how these could be institutionally supported. Some of them are considering the introduction of regional currencies to facilitate the strengthening of ties and trust and to develop local wealth indicators. The goal is to 
replace the overemphasis on competition with that of cooperation and to involve the population in the process of what economies should deliver on and how.

The movement is strongest in Austria, northern Italy and Germany. Felber's 2011 book The Economy for the Common Good has been translated into Spanish, Italian, Finnish and French and the website is also available in Polish but not in Finnish. This rapidly growing movement is a brilliant example of how different pioneer activities align behind a clearly formulated repurposing of their small systems with a plan to drive the transformation of the overarching regime systems.

Of course this does not mean everyone involved will and can find the same incremental steps to become Common Good supporters. While the strongest criticism from the mainstream predicts that the focus on re-localization and regionalization will lead to a collapse in productivity and wealth creation, the more nuanced observers point to the creativity with which the old and unchanged business practice might now be branded differently. Some measures that would be unavoidable anyhow, like providing training for employees to, for example, catch up with newest IT trends, can now be declared common good measures. Using the common good narrative as an image campaign might then lead to better sales and therefore more profane profit-while not much else changes (Exner 2011). As mentioned above, I think it is important to check such practices by flagging them and assessing if further incremental steps are to follow. I do not think that a movement and vision should be dismissed unless such practices become the norm. Exner lists two businesses out of the group of 1811 and his judgment is based on the public statements of the managers rather than proper investigation.

The vision as formulated by the movement itself is to be an open, adaptive learning community with potentially global reach. It seeks to create self-reliance and more independence for each of the regions but also changes in the overarching regime structures so that the normal or hegemonic way of thinking and doing business is transformed. Here the participants point to three hegemonic assumptions: that humans (should) only pursue their self-interest, that without the intention of gain there is no entrepreneurial engagement and that competition is always the most efficient way of organizing production and consumption processes.

\subsection{Pioneering Civil Society: Transition Towns for Resilient Local Solutions}

Originally emerging in the United Kingdom, the Transition Towns movement has spread across Europe and beyond. While the Common Good network already had a strong focus on the local embeddedness of its members, the Transition Town movement makes 'reflexive relocalization' its core stance. The term 'reflexive' is important because it highlights the way that the process is driven by communities. It is done with a clear system view that envisions improved resilience of a town and 
its people in the face of growing megatrends like climate change, rising energy prices and economic crises.

The term 'resilience' is used here to define a particular structural characteristic of a complex system. Resilient systems are those that are able to bounce back or recover their strength quickly after a shock or crisis. In the case of human systems, like cities or economies, this means that the functioning of basic services for the population will be quickly restored.

Such restorative capacity is higher if several alternative processes can deliver on important system outcomes (diversity), if these are not all easily hampered by the same shock (decentralization) and if several processes keep their potential to increase output if necessary (redundance). Resilience is therefore a very dynamic and not easily visible or measurable quality. High resilience usually means high levels of the self-organizing capacity of a system, so that it can learn, create and redesign processes essential to their functioning. The mechanistic view of systems in the mainstream economic paradigm will often lead to the sacrifice of this quality for efficient static stability and higher productivity.

Rob Hopkins, one of the leading figures in the Transition Town movement and author of The Transition Handbook: From Oil Dependency to Local Resilience (2008) adds a sociopolitical component to his definition: Resilient sustainable communities are structured along three principles. These are their 'diversity' of life-supporting solutions or livelihoods, 'modular structuration' with buffers to the outer systems that increase self-reliance possibilities, and 'tight feedback loops' that bring the results of actions closer to those responsible for them (Hopkins 2008: 5556). The latter is generally regarded as important to ensure that negative developments are picked up more quickly.

Resilience has also become a frequent term in the context of natural catastrophes that destroy infrastructure or limit the possibilities of shipping and flying goods around the globe. Recent examples are the Japanese tsunami that caused the 2011 Fukushima disaster and energy system breakdown and the Icelandic volcano eruption that threatened the United Kingdom's globalized food supply chains in 2010. Here, as in the WEF 2012 Global Risk Report, it was primarily the infrastructure and its control chain that was assessed for resilience. The more decentralized units with decision-making powers and local knowledge combined were much faster in restoring the energy supply to people than centralized ones with hierarchical control. From an exchange-value-focused perspective on process design, the latter are of course much more efficient.

We see that the notions about which processes are promising and seem valid depend on which overarching system view one adopts. Transition Towns do not treat the economic system as the overarching one but as a subordinate means to ensure that human need satisfaction can be achieved in alignment with the natural laws of the ecological system. An explicit part of increasing self-reliance and resilience means turning away from certain massive economies of scale that are only possible under systems with a high division of labor. This may lead to decreases in the overall availability of consumption goods, but could lead to the higher quality and longevity of each good produced and to lower risks in terms of 
supply chain interruptions when transport or credit in one part of the chain is hampered. Meanwhile, sustainable communities, according to Hopkins, do not subscribe to a culture of consumerism but seek to link "satisfaction and happiness to other less tangible things like community, meaningful work, skills and friendship" (Hopkins 2012: 20-21).

Here we find a direct connection with findings on human well-being and its origins. It was insightful to see that some workshops of the Transition Town movement were using Max-Neef's human need matrix to discuss a diversity of strategies for a high quality of life beyond 'having' things. This also ties back to the criticism of ecological economists like Paul Ekins and Robert Costanza in Chap. 3, who state that the social utility gained through the human interactions during production processes should get much more attention when assessing productivity. Meanwhile, many resilience researchers also emphasize the importance of trust as a core ingredient to well-functioning, adaptable communities and individual perceptions of well-being.

The 2012 High Level Panel on Global Sustainability did not get this far in its report to the UN Secretary-General before Rio+20. Resilient People, Resilient Planet: A Future Worth Choosing describes the world system as volatile and uncertain, and suggests that the panel start their recommendations with a call to "empower people to make sustainable choices" as a response to this. It does not seek to empower people to build their own communities though, but rather focuses on how the social safety nets of governments are set up so they can be resilient in times of structural change, and how disaster risk reduction and adaptation programs could be improved (United Nations Secretary-General's High-level Panel on Global Sustainability 2012: 46-47).

The Transition movement, on the other hand, makes these self-empowerment processes the essence of its existence and adapts them to systems or communities of any size, not just towns. Its mission is summarized as follows: "to inspire, encourage, connect, support and train communities as they adopt and adapt the transition model on their journey to urgently rebuild resilience and drastically reduce $\mathrm{CO}_{2}$ emissions." The seven principles for guiding such processes in towns are set out by Hopkins and Peter Lipman on the Transition Network website (transitionnetwork.org) and can be summarized as follows:

1. Positive Visioning: Campaigning for rather than against something.

2. Help People Access Good Information and Trust Them to Make Good Decisions: Raising awareness and hearing many opinions lies at the core of rational decision-making.

3. Inclusion and Openness: Banning 'them and us' thinking and reaching out to all subsystems in the town, early in the process.

4. Enable Sharing and Networking: Acknowledge everything, including stories of failure.

5. Build Resilience: With the primacy of environmental resilience, change food, energy and economic systems in the town and across governance levels. 
6. Inner and Outer Transition: Worldviews and belief systems can change and create something different and need not cause fear.

7. Subsidiarity: Self-organization and decision-making at the appropriate level (Hopkins and Lipman 2009: 7-8).

We can clearly see how many of these principles fly in the face of mainstream models. Actors are explicitly requested to change their way of thinking and being and to share instead of compete. The processes of providing energy and food are intentionally made less efficient so that they become more resilient. The economic system is analyzed as a subset of SES's that can and should fundamentally change if it hurts the balance of ecological reproduction circuits. It is therefore not the resilience of the economic system that successful development strategies should pursue but that of the ecological systems with biophysical qualities that can be irreversibly altered.

This point is important because otherwise 'resilience,' as a concept, might be used in as undifferentiated a fashion as 'efficiency.' Resource efficiency is basically always desirable, but making efficiency a core value in and of itself, for all processes, is taking it too far. The same holds true for resilience, as the financial system shows nicely. From a sustainability perspective it is utterly damaging, but its immaterial qualities mean that very quickly many new financial products and instruments emerge if others are ruled out. It thus shows a great self-organizing capacity and has bounced back from the 2008 crisis without significantly changing its functions, structure, identity or internal connections. Instead, the financial system would require a decrease of resilience so that transformation could take place.

Thus, the goal of improved resilience can only be of added value for sustainability when the purpose and setup of the system in question is one in line with what sustainable development on the macro scale requires. The Transition Town principles make this distinction (see point 5) and the idea has been exported to many places across Europe. Out of the ongoing experiences a number of guidelines, ingredients and practical steps have emerged on how to set up a community initiative. These can be found on transitionnetwork.org. Each transition or transformation of a community is expected to take 20 years or longer. The website also includes a map of where initiatives from across the world are registered, and in mid-2015 it had 479 official initiatives in 43 countries, which can be located through an interactive map at http://www.transitionnetwork.org/initiatives/map.

From the MLP point of view, these initiatives form perfect niches ready to build coalitions for regime change. Yet, some critics lament the absence of a more explicit political agenda that would be able to reach just that. They find the 'anything goes' character behind the initiatives too lofty and the building of windmills, barter trade networks and permaculture gardens too individualistic. Moreover, even if single towns become more resilient this would not necessarily change the overarching regime structures that push economies out of Planetary Boundaries. Some of this criticism may be true, in particular when rich communities work on making their own backyard lovely but do not feel much responsibility for those worse off. 
On the other hand, I find it important to maintain the distinction between pioneers and change agents made by the WBGU report reviewed in Chap. 2: one and the same group or individual cannot necessarily do everything. Testing deviating practical solutions or business models is much more work than following the well-trodden path dependencies; it often binds all of the available resources. To expect the same pioneers to also develop political campaigns might well be unrealistic. During my time in Brussels, for example, politicians in favor of rewriting the green policy framework were urging civil society to provide studies and communicate how, for example, renewable energy technology or biologically degradable products could replace many dirty solutions if regulation allowed for them to be scaled up. These innovations are typically developed by SMEs that simply do not have the spare resources for significant lobbying. On the other hand, the big potential losers (the polluters and so on) do, and they shout loudest. Thus, while some people in Transition Towns can focus on experimenting with the new practical solutions, others could engage in political processes.

Or other change agents, like myself, could pick up on these examples to make them known and fit them into a political agenda. Networking support, political engagement, and visibility have been growing significantly in recent years. Transition Towns or initiatives are crucial examples of how system innovations that link an update in physical technologies like renewable energy with those of the social technologies around them, will have much more impact for sustainability than solar panels alone.

If the ecological systems and their importance for future human well-being are prioritized and the least destructive technologies chosen for need-satisfaction strategies that do not rule out sufficiency, we have a great example of system-repurposing. It echoes the two key points in the Brundtland definition of sustainable development: satisfying human needs in the long term and choosing processes that will not threaten the planet's ability to replenish the resources to do so. Such progress can only be measured with indicators that go beyond GDP.

\subsection{Pioneering Governments: Beyond GDP Measures as Development Frames}

Indicators frame the way we view things, which aspects we pay most attention to and which rationales are reproduced. Since the Brundtland Report there have been many indicator initiatives aimed at going beyond GDP at all levels of governance and some of them have gained quite a lot of public attention. The UN HDI, for example, first launched in 1990, expanded per capita GDP measurement to include education and life expectancy in its overview of successful country development. The GPI discussed in Chap. 3 seeks to correct GDP numbers according to the natural capital destroyed and the negative social impacts that this method of wealth generation causes people. 
Many of these 'headline indicators' are meant to capture public attention, which is more easily done with one number than with a dashboard. Amending or correcting GDP numbers with indicators has been an incredibly important step in expressing the fact that capital substitutability accounting - the essence of weak sustainability processes - fails to capture the real state of natural, social and human capital and therefore the prospects of future development. The headline indicators or indices are, however, not the right tools for the design of actual system innovation processes. For this we need disaggregated information about causalities and correlations between the different elements measured and also sociopolitical engagement with the questions of how to weight potential trade-offs between these elements. If we do not dissect statistics and models in this way, their values and information are difficult for non-experts to understand and they can become a source of hegemonic power, rather than a telling insight for improved governance capacity and consensus-building.

The actual design process of measurement schemes with which to monitor future developments is therefore at least as important for democratic system innovation governance as finding exactly the right numbers. The biggest challenge is apparently to dethrone the dominance of economic indicators over social and environmental aspects of development. This observation held for all countries in the UN Synthesis of National Reports for Rio+20 on the implementation of sustainable development strategies:

Today's challenge is chiefly implementation... .. This is largely due to integration, inclusion, and coherence challenges.. .. Economic growth is still the chief priority for most governments, and although they increasingly integrate poverty alleviation and other social concerns into development planning, the integration of environmental considerations has lagged. The review of national reports revealed little evidence that countries see sustainability as contributing to growth; at best, governments see sustainability as compatible, or at least not interfering, with growth, but there is little indication that these countries see environmental sustainability as necessary for long-term growth (UNDESA and UNDP 2012: 2).

The report lists five priorities for tackling this implementation roadblock and brings new measurements of progress and improved democracy and empowerment for bottom-up change to the forefront:

If national systems look only at economic performance, then people cannot hold their leaders accountable when it comes to progress on social and environmental matters. New and more tailored metrics as well as bolstered data collection systems and capacities are needed in both public and private sectors. Such metrics will be critical to the post-2015 development agenda, in particular to the sustainable development goals (UNDESA and UNDP 2012: 5).

Unfortunately, the SDGs only list the development of GDP-complementing measurements for progress as the very final target (17.19) under SDG 17 on means of implementation and global partnerships. This gives it much less prominence than the multifarious targets on GDP growth scattered across the other 16 goals (UN 2015). 
This does not mean, however, that the progress metrics community is not continuing its work. Reports like that of the Stiglitz-Sen-Fitoussi Commission on the Measurement of Economic Performance and Social Progress in 2009 have already shown a growing consensus that a small dashboard of lead indicators that are easy to understand would be most helpful. These should mix monetary as well as physical measures for objective progress. There is still more debate about if and how to include subjective happiness data from surveys. Some regard it as too vague and qualitative for statistics, others say that this is indeed the problem: You can never understand a system and actor motivations if you do not ask people about their experienced reality (Stiglitz et al. 2009).

One astonishing example supporting the latter argument is the OECD's 2013 Health at a Glance report in which a question about whether respondents felt healthy was answered positively by $89.5 \%$ of Americans but only $30 \%$ of Japanese. According to objective data, however, Japan has the second highest life expectancy figures in the world and very high scores in terms of the number of hospital beds, MRI and CT scanners, the length of stay in hospital, and the number of times people go to the doctor. In the United States life expectancy is four years shorter and rising much more slowly than in other OECD countries. Its obesity rate is twice that of others and $15 \%$ of the population live without health coverage, despite the world's highest per capita expenditure on health care (OECD 2013a).

So without talking to people directly, much insight about experienced well-being and need satisfaction may be missed. In addition, the processes of creating indicators with the people whose development they should measure already involve many mindshifting effects for better understanding of trade-offs or even the possible overcoming of trade-offs if goals and processes were changed. These effects create ownership and better acceptance for future policy measures and would rank high in the categories of social or human capital improvement for economists.

OECD and UNDP consultants Jon Hall and Louise Rickard have studied seven beyond-GDP indicator processes around the world for the Bertelsmann Foundation. They have pointed to the following happy side-effects of the bottom-up participation recommended by the UN: the strengthening of democratic processes with the direct inclusion of the population in the overall goal and purpose-setting of future policy directions, which also allows for a widening in perspectives on all sides as to how different single aspects hang together and why they are important to whom; policy coherence and acceptance are also increased through ongoing processes toward finding common ground or a clear identification of antagonistic positions and trade-offs that can then be dealt with explicitly rather than remaining as unresolved undercurrents. Linking this back to resilience, the study also found that such processes build capacity for constructive deliberation and enable participants to become more proactive in other sociopolitical contexts as well (Hall and Rickard 2013: 11-12).

Thus, if carried out in a participatory manner, many such indicator processes already lead to social benefits and reflexive processes around which values, norms and the goals a community wants to base its development. It also improves 
potentials for monitoring, communication and innovation, since more people know about the drivers of current challenges.

These paradigm-shifting and change-inducing effects have also been summarized by Joseph Stiglitz, the Nobel Prize-winning economist and head of the commission mentioned above, in a presentation to the Australian Productivity Commission:

Part of the objective of rethinking our measurement systems is to generate a national and global dialogue:

- On what we care about

- Whether what we are striving for is achieving what we care about

- And whether this is reflected in our metrics (Stiglitz 2010: 15).

However, these sociocultural benefits are still not reaped in many indicator schemes, as many examples of rather technocratic sustainable development strategies show. In a major research endeavor between 2012 and 2013, the Bertelsmann Foundation and the Canada-based International Institute of Sustainable Development (IISD) developed an extensive criteria set for the analysis of 35 sustainable development strategies from around the world. They found that the best practice examples included those that have a clear mission statement or Leitbild connecting the otherwise abstract goal of sustainability with culturally vibrant local notions of what constitutes a good life.

The top examples here were the GNH Index from Bhutan, the Buen Vivir (Good Living) social philosophy in South American countries like Bolivia and Ecuador and the Finnish vision of "quality of life within sustainable societies." In general terms the importance of linking sustainable development ideas with notions of quality of life was a common theme among the successful examples (Bertelsmann Stiftung 2013: 15-16).

A review of the Bhutanese case follows, as it was the most successful strategy in the Bertelsmann/IISD study and served as a pioneering example in UN high-level roundtables for a "new development paradigm" for the post-2015 development agenda and its SDGs. It highlights how a development goal different from that of GDP has played out since the 1970s.

The development aim of GNH was set out in 1972 by Bhutan's fourth king, Jigme Singye Wangchuck. He presented it as the logical outcome of the legal code which sealed the unification of Bhutan in 1729, and stated that, "if the government cannot create happiness ('dedidk') for its people, there is no purpose for the government to exist" (Ura et al. 2012: 6). This is not very different from the US Constitution of 1776, which declares "life, freedom and the pursuit of happiness" to be the basic rights of each individual and their protection to be the duty of the state. However, Bhutan has made this duty an explicitly monitored and societal endeavor instead of the individualized consequence of high economic growth.

Before the creation of their indicator system, Bhutan's general idea was understood as being "development with values" that were conducive to promoting collective happiness by the creation "of enabling conditions where people are able 
to pursue well-being in sustainable ways." Five of these values were, and are, fundamental. They are a holistic view of people's needs, be they spiritual or material, physical or social; balanced progress toward GNH with an emphasis on preventing one dimension from outstripping others; a collective and all-encompassing view of happiness; sustainability, so that well-being is pursued for current and future generations; and a notion of equity such that levels of well-being should be similar across society (Ura et al. 2012: 7).

The big difference from Western concepts lies in the idea that spiritual and material development are viewed as two complementary and mutually reinforcing elements of human progress. Responsibility for nature and motivations regarding the well-being of others are integral to this view of happiness because, say researchers of The Centre for Bhutan Studies in the book An Extensive Analysis of GNH Index (2012): "We know that true abiding happiness cannot exist while others suffer, and comes only from serving others, living in harmony with nature, and realizing our innate wisdom and the true and brilliant nature of our own minds" (Ura et al. 2012: 8). This view was already present in the 1999 government strategy paper Bhutan 2020: A Vision for Peace, Well-being and Happiness, which had a very explicit focus on the long-term and recognized the importance of economic growth for such a poor country but sought to keep the balance between material and non-material as well as spiritual development. The five overarching goals then were human development, culture and cultural heritage, a balanced societal development benefiting everyone, good governance and protection of the environment (Bertelsmann Stiftung 2013: 70).

The overall development strategy was always embedded in environmental programs and sustainable development strategies until the 2008 constitution declared GNH to be the official guiding principle of the country's development and introduced the new measurement system. It is important to note that this index is not intended to measure happiness as such, but to "orient the people and the nation toward happiness" by improving their conditions (NDP Steering Committee and Secretariat 2013: 30).

In practice this has led to the formulation of four strategic pillars of policy planning. These are sustainable and equitable socioeconomic development, environmental conservation and the preservation and promotion of culture and good governance. In order to specify and measure progress in these areas, an index with nine dimensions was created. They include rather common dimensions like living standards, health and education, ecological diversity and good governance, but also unique and important elements: psychological well-being, which includes, but goes beyond, subjective well-being reporting; time use; community vitality; and cultural diversity. Each dimension has a set of between three and five indicators or questions which are used for taking representative surveys and are analyzed according to a total of 124 variables.

Except for the cultural, psychological and spiritual components, we find a lot of similarities between the Bhutanese dimensions and the 11 dimensions of the OECD Better Life Index which launched in 2011. These are housing, income, jobs, work- 
life balance, health, life satisfaction, safety, civic engagement, environment, community and education (OECD 2014a).

In an ongoing, non-representative online questionnaire, the OECD asks visitors to their website (oecdbetterlifeindex.org) to weigh the importance of these dimensions. Regardless of country or age group people put health, education, life-satisfaction and work-life balance highest. Income is the second lowest and community the least important. This of course is a snapshot of opinion of a small group of people who are probably already interested in the issue or they would not have ended up on the website. Also, this approach is strongly focused on today's experience of life and lacks indicators that could delve deeper into the sources of what could sustain delivery on those dimensions in the future. The environment, for example, is reduced to nothing more than clean water and clean air.

The OECD's How's Life? 2013 report has therefore added a long section on this in which it discusses how measuring social, environmental, human and economic capital stocks is essential to securing quality of life in the future (OECD 2013b). Yet, this economic perspective leaves one with the impression of a basic collection of input factors rather than a systemic understanding of how the various dimensions relate to each other and co-develop as embedded systems. This is the strength of the Bhutanese approach, with its focus on values and culture.

Maybe the most innovative feature of the GNH strategy, however, is the fact that the survey results inform the core of government practice. Five-year policy plans respond to findings that can be differentiated by region, gender, profession, age group, etc., to identify which interventions and resource allocations are important to support those reporting the least happiness (Ura et al. 2012: 8-11). They are formulated in multilevel, multi-stakeholder processes and local consultations while each new law is evaluated in terms of its impacts on GNH dimensions and indicators. Important strategy plans include complete electrification, tripling hydro-power generation, improved independence in food provision, $100 \%$ organic agriculture, a low ecological footprint, economic diversification, reduction in the use of fossil fuels for transport and the development of sustainable expensive tourism (Bertelsmann Stiftung 2013: 61-83; Ura et al. 2012: 1-15). All of these strategies are assessed from the holistic GNH view.

Since Bhutan's surveys have only been done twice to date, clear trends within these metrics are hard to map. But on conventional measurement schemes its development is better than other South Asian and comparable states worldwide in terms of poverty reduction, improving HDI rates, constant economic growth and successful environmental protection. The prior GNH framework has also guided a stable and still ongoing transition since the 1970s that involved moving from an absolute monarchy to a constitutional monarchy and finally into a constitutional democracy. This process was initiated by the fourth king and finished by Jigme Khesar Namgyel Wangchuck, the fifth and current monarch in 2008, when a widely discussed constitution was signed into law and first elections were held.

Since the 1980s, Bhutan's life expectancy has gone up by 20 years, its birth rate has gone down from 6.55 to 2.4 children per woman, infant mortality has halved and years spent in school have gone up by seven to the OECD average of 11 years. 
Its per capita GDP is 13 times higher and unemployment is a mere $4 \%$. At the same time Bhutan has managed to increase the area under forest cover from $50 \%$ in the 1970 s to $80 \%$ and inserted into its constitution a clause that this must not fall below $60 \%$. The total of its protected nature areas amounts to $50 \%$ of the surface of the country and the ecological footprint of each Bhutanese is 0.8 ha, well below the world average of 2 ha. It has pledged to keep its development climate neutral and hydro-power is supposed to be the prime energy source by 2020 , even allowing for exports that would reduce Bhutan's still significant dependence on official development aid.

All is not rosy in Bhutan, however. In the $2010 \mathrm{GNH}$ survey only $41 \%$ of people passed the sufficiency threshold for happiness as defined by the government, which included only $37 \%$ of those living in rural areas. Climate change is threatening hydro-power plans and floods risk damaging the main towns as most of them sit at the bottom of a long valley in the Himalayan mountains. Urbanization and the lack of jobs for educated young people wishing to work in offices leads to problems and a lot of migrant workers from India doing the hard physical work. The media and tourism-based exposure to the mainstream global culture of consumerism seems to increase tensions. Young people who have studied abroad are also more critical of the lack of entrepreneurial spirit and availability of goods.

This is one of the core reasons why the promotion of GNH values and ideas in educational institutions has become a strategic goal. All teachers have been given training in green ideals, which involve ecology as well as intellectual, academic, social, cultural, spiritual, aesthetic, and moral values (Bertelsmann Stiftung 2013, 61-83). All schools have meditation on their curricula, even if only for a minute for small children. Bhutan's 2013 report to the UN, Happiness: Towards a New Development Paradigm, makes reference to well-being and neuroscience study results on the positive effects of regular mindfulness practice on health and quality of life and also social relationships and productivity (NDP Steering Committee and Secretariat 2013: 35).

In the report, Bhutan also freely admits that "as with any new attempt at multidimensional social assessment," there are still a number of technical and methodological challenges in GNH implementation, both the measurement, (interpretation of its mathematical formula, questions about correlations between results when comparing regions and groups, robustness of data on the small scale and the wording of particular questions) and the communication of policy-relevant results and their translation into concrete political measures (NDP Steering Committee and Secretariat 2013: 31).

However, the GNH data confirms many of the well-being studies referred to in Chap. 3. Happiness is high when people live in conditions providing safe areas where they trust their neighbors, have ample economic security to provide the necessities of life to their families, health, clean air to breathe, safe water to drink, green spaces for recreation, healthy natural resources to provide the necessities of life, knowledge rather than ignorance, strong social networks and a sense of belonging to a culture and community (NDP Steering Committee and Secretariat 2013: 33). In addition to these objective conditions great emphasis is put on the 
inner transformation of mind-sets and behaviors so that individuals can skillfully enjoy these potentials, otherwise people may well continue to feel miserable even under such circumstances.

The report concludes that mindfulness as the "cultivation of non-judgmental, non-reactive, metacognitive awareness of present-moment experience" is one important "happiness skill" as are the conscious practices of gratitude, empathy, and patience. Referring to studies documenting higher levels of life satisfaction, meaning and happiness from volunteerism and community service, the report adds that "these and related skills combine to build the capacity for citizenship, and hence for engagement in processes of social change, that help people develop 'not just better goals, but better means as well."” (NDP Steering Committee and Secretariat 2013: 35) Five principles were suggested for an alternative vision recognizing the complexity and interrelatedness of human reality and developed into a proposed paradigm for the UN negotiations around the Post2015 development agenda (now 2030 Agenda for Sustainable Development):

(1) transformation in what we value;

(2) reconsideration of the purpose of development;

(3) re-orientation of humanity towards service;

(4) recognition of our interconnectedness; and

(5) an ethos of cooperation (ibid.: VI-VII).

This view is very much in line with the mind-sets of common-good orientation and community resilience discussed above but another total deviation from mainstream ideas on humans and their relationships. Figure 4.1 encapsulates the paradigm with the nine outcome dimensions of GNH and their wider conceptual embedding.

Transformation researchers will particularly appreciate the arrow pointing from 'societal happiness' back to 'needs' and the 'Holistic Development Agenda' described as transformative with interconnected solutions: none of these are viewed as independent, natural or universal laws but as an integral part of continuous change, depending on the state of societies and the planetary resources drawn upon.

What struck me when visiting Bhutan was the humility with which even high officials like the princess or ministers say that they have not reached the state to which they aspire. The phrase that reflexive transformation researchers might find most impressive was that they are conducting a "living experiment with the truth."

Of course, there is also plenty of criticism. The least qualified still sneer that a country with a monarchy lacks the credibility to speak about good governance, ignorant of the fact that democratic elections were introduced almost a decade ago. Others point out that small agricultural and Buddhist Bhutan can hardly be a role model for huge industrialized countries of multiple religions. Then the refugee drama of the early 1990s remains a massive black spot on Bhutan's history. A movement toward the democratization and possible independence of the south, where many Nepalese people lived, was countered with a nationalist movement by the king. Apparently when he found out about connections the underground 


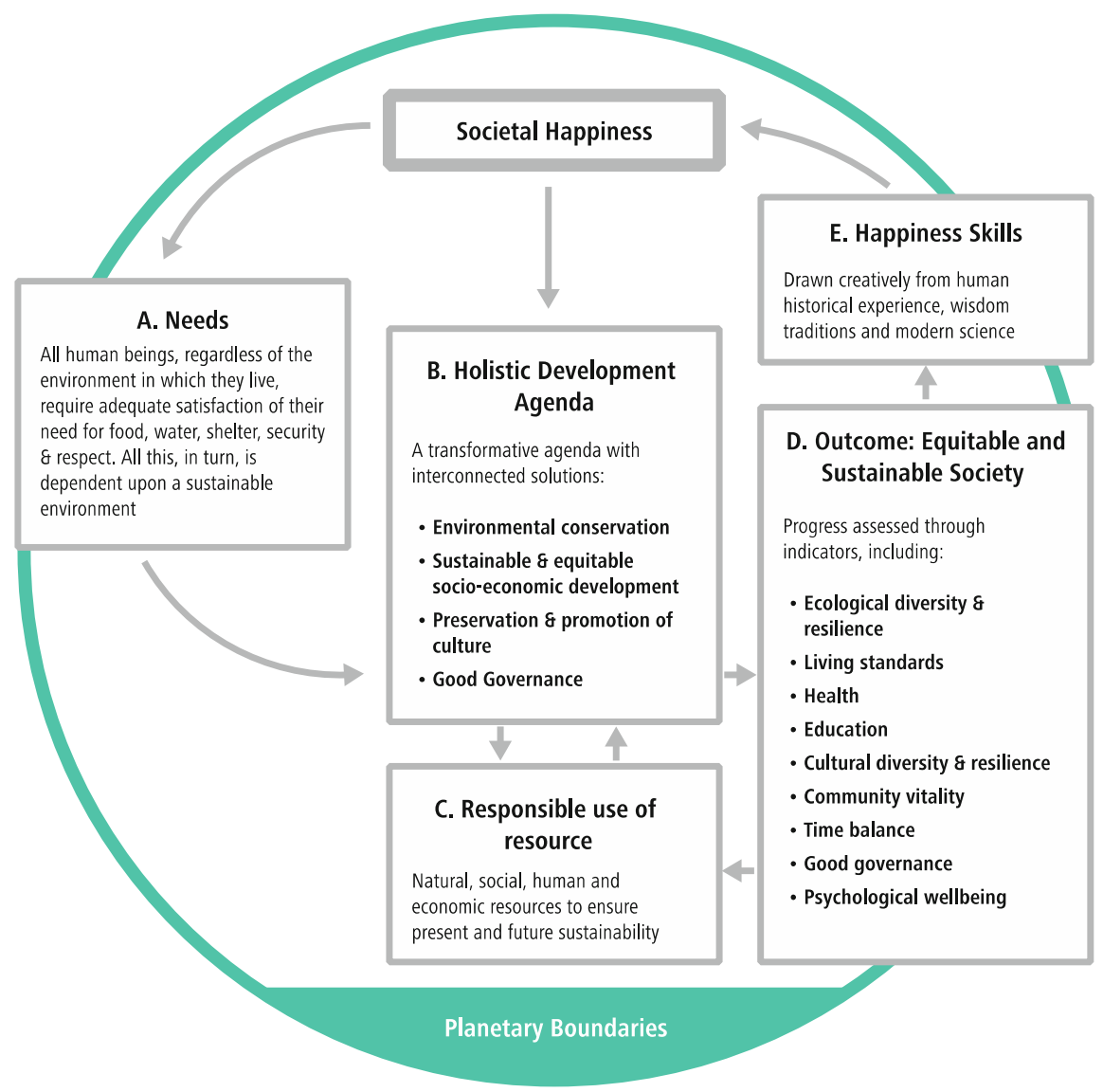

Fig. 4.1 A new development paradigm of well-being and happiness. Source Based on NDP Steering Committee and Secretariat (2013: 20)

activists had developed outside Bhutan (especially in India), he ordered in the country's newly trained army and up to 100,000 people fled the country. The numbers are unverified but would amount to one sixth of the population at that time. Critics argue that this event casts such a shadow that cherishing Bhutan as a positive development pioneer is impossible. Speaking to government representatives during my stay gave me the perspective that this country of 800,000 people stuck between the competing super powers China and India was worried about its very existence when it found out about the Indian support for the movement for government reform and possible independence.

I am far from able to judge any of these events in the early 1990s. What I can say is that the later policy frameworks, and even the GNH index itself, are the result of international collaboration. What I can also say is that people are quick-far too quick - to talk about the scheme being discontinued. After the elections in May 
2013 the new prime minister, Tshering Tobgay, was less enthusiastic about making GNH the top priority and not interested in touring the world to promote it. But the scheme is inscribed into the constitution and thus I found it surprising to see the Wikipedia entry for GNH quickly changed into past tense, claiming that it had been abolished. The only source for that was a New York Times article in which no proof was to be found. Later articles and speeches of Tobgay, like this quote in The Guardian, cast a different light:

\footnotetext{
What's changed with our government is that we believe our priority must be at home ... We must remove the obstacles to GNH and be true to it within the country... But the job of government is not to lead debate; it is to implement the principles at home. The world should not expect too much from us, and we should not expect too much from ourselves (Confino 2014).
}

So instead of using GNH as a brand and becoming complacent about it, Tobgay believes Bhutan should work on the unprecedented divorce rates, domestic violence, drug abuse and suicide (ibid).

Reading such statements makes me wonder when Western countries will learn from this cultural trait: a respectful culture of experimentation seems like the best humus for radical incremental transformation strategies. One global movement that also works in this direction but originated in the West is On the Commons. It shares many of the same values and the community well-being mind-set. It can thus serve as an inspiration for all those who feel that Bhutan's model is too dependent on its Buddhist culture to have wider appeal.

\subsection{Pioneering Governance Systems: Commoning as a New Stark Utopia}

The term 'commons' is mentioned in economic thinking and governance primarily in the context of the idea of a "tragedy of the commons" in which freely available natural resources like land, forests, oceans or the atmosphere are used unsustainably because everyone can pursue their own benefits by exploiting them or dumping emissions and waste onto or into them. The selfish-competitive actor view therefore concluded that only private property rights or strict state control was suitable to deter such action. As a consequence we frequently hear about market failure or state failure when this is not successful.

Nobel laureate Elinor Ostrom, one of the leading thinkers that inspired this movement, rejected the universal law that all humans are selfish and that policy or competition somehow have to rein in their destructive actions. She and her colleagues also took a closer look at whether there are really only two types of goods that would justify being satisfied with two prototypical governance solutions. In her 2009 Nobel speech, Ostrom summarizes the amendments that she and her colleagues made to mainstream economic ideas. First, they widened the definition of 
Table 4.1 Four types of goods and their forms of scarcity

\begin{tabular}{l|l|l|l}
\hline \multirow{2}{*}{} & \multicolumn{3}{|l}{ Subtractability of use } \\
\cline { 2 - 4 } $\begin{array}{l}\text { Difficulty of } \\
\text { excluding } \\
\text { potential } \\
\text { beneficiaries }\end{array}$ & High & $\begin{array}{l}\text { Common-pool resources: } \\
\text { groundwater basins, lakes, } \\
\text { irrigation systems, fisheries, } \\
\text { forests, etc. }\end{array}$ & $\begin{array}{l}\text { Public goods: peace and } \\
\text { security of a community, } \\
\text { national defense, knowledge, } \\
\text { fire protection, weather } \\
\text { forecasts, etc. }\end{array}$ \\
\cline { 2 - 4 } & Low & $\begin{array}{l}\text { Private goods: food, clothing, } \\
\text { automobiles, etc. }\end{array}$ & $\begin{array}{l}\text { Toll goods: theaters, private } \\
\text { clubs, daycare centers }\end{array}$ \\
\hline
\end{tabular}

Source Based on Ostrom (2009: 413)

'means' or 'goods' so that they captured real accessibility and scarcity or non-scarcity (Table 4.1).

The mainstream paradigm differentiates private goods that are both excludable and rivalrous (people can be excluded from usage unless they pay) and public goods that are both nonexcludable and nonrivalrous (even if people do not pay they can consume the goods and this does not limit the consumption by others either). The excludable/rivalrous would have to be organized by the market and the nonexcludable/nonrivalrous by government control. In the latter case, people could influence the usage either by consuming or voting. Table 5 shows that Ostrom rejected this clear-cut juxtaposition and argued for more differentiated characterizations. Substractability of goods replaces rivalry of consumption and refers to the notion that consuming a good will reduce the level of the resource available for others and can be either high or low, not simply on or off. In addition, two more goods are defined: "common pool resources" contain most of the ecosystems and their provisions for human survival whereas "toll goods" have also been called "club goods" as they involve a smaller group of individuals or groups providing themselves with nonrivalrous goods and services from which only they benefit and non-members are excluded (ibid).

Ostrom and her colleagues then went on to define an analytical framework of the most general set of variables that institutional analysis would need in order to capture a diversity of human-made institutional settings, including markets, private firms, and governments, but also families, community organizations, and civil society organizations. These captured rules in use and the ways they evolve over time, the attributes of a community in terms of knowledge, social capital, participation, heterogeneity, and also biophysical conditions. The results show that there are many ways to avoid the tragedy of the commons. Common pool resources may not need to be divided up into private ownership or state control, especially once one assumes that actors know each other, can communicate and learn. So while Ostrom acknowledged that turning one or two rules into seven or eight "has been upsetting to scholars who wanted to rely on simple models of interaction among humans," her team's extensive research of case studies led them to distill eight "design principles" for successfully sustained governance regimes (ibid.: 421-422). Their summary is so short that I cite it completely: 
1A. User Boundaries: Clear and locally understood boundaries between legitimate users and nonusers are present.

1B. Resource Boundaries: Clear boundaries that separate a specific common-pool resource from a larger social-ecological system are present.

2A. Congruence with Local Conditions: Appropriation and provision rules are congruent with local social and environmental conditions.

2B. Appropriation and Provision: Appropriation rules are congruent with provision rules: the distribution of costs is proportional to the distribution of benefits.

3. Collective-Choice Arrangements: Most individuals affected by a resource regime are authorized to participate in making and modifying its rules.

4A. Monitoring Users: Individuals who are accountable to or are the users monitor the appropriation and provision levels of the users.

4B. Monitoring the Resource: Individuals who are accountable to or are the users monitor the conditions of the resource.

5. Graduated Sanctions: Sanctions for rule violations start very low but become stronger if a user repeatedly violates a rule.

6. Conflict-Resolution Mechanisms: Rapid, low-cost, local arenas exist for resolving conflicts among users or with officials.

7. Minimal Recognition of Rights: The rights of local users to make their own rules are recognized by the government.

8. Nested Enterprises: When a common-pool resource is closely connected to a larger social-ecological system, governance activities are organized in multiple nested layers (ibid. 422).

While these are the empirical results of researchers observing and coding variables, there is now a movement that translates these design principles into a principled approach to governance that could be applied beyond the typical common pool goods. Commoning thus captures a mind-set that favors collective ownership and development. Regarding freely available natural resources, it holds the view that they are the common heritage of mankind, so that everyone has an equal entitlement to use them but also equal responsibility to protect them. Each generation should only take to the extent that leaves future generations with similar wealth. Also, jointly produced output is viewed as a common good rather than an asset to be divided up into individual returns on the production factors invested. Thus, in addition to being co-stewards of that which Earth and our ancestors have provided, everyone is seen as a co-proprietor of wealth created. Commoning solutions therefore seek to define new systems for reproduction that go beyond the typical market and state patterns in political economy. They break with their private or public ownership logics by creating governance and entitlement structures tailored to the type of good and local circumstances. Often this will lead to envisioning and enacting non-commodified production and consumption solutions among peers that are marked by joint responsibility for the maintenance of the system created.

The book The Wealth of the Commons: A World Beyond Market and State comprises 73 essays from thinkers and practitioners in the commoning field (Bollier and Helfrich 2012). The commonalities within this community are described as "an overarching worldview." They comprise a set of social attitudes, commitments and political philosophy, and even a spiritual disposition, all shaping an experimental means of strategic change (Bollier and Helfrich 2012: xii-xiii). 
While a single definition of the commons or commoning does not exist, one website, onthecommons.org, is central to the movement and summarizes the core of this paradigm or framework in Fig. 4.2.

The inner core principles characterize all commons initiatives:

- Equity-Everyone has a fair and just share of social and natural resources that belong to us together.

- Sustainability - Our common wealth must be cared for so that it can sustain all living beings, including future generations.

- Interdependence - Cooperation and connection in our communities, around the world, and with our living planet is essential for the future (On the Commons 2012).

The second ring describes practice characteristics and hints at what social life (Lebenswelt) would feel like if commoning became the common-sense or normal way of viewing and doing things. Here we find quite a few overlaps with the 'novel' dimensions of the GNH index like cultural and community vitality (belonging), the connection of one's own happiness with that of the wider community (responsibility), and the spiritual aspects of psychological well-being. The following examples are given for the quality of relations and processes:

- Shared Governance-Everyone is engaged in gathering information, making decisions and exercising power to steward common resources.

- Deepened Responsibility-Together we claim the power to repair inequity, restore our common inheritance and expand opportunities for human fulfillment and planetary resilience.

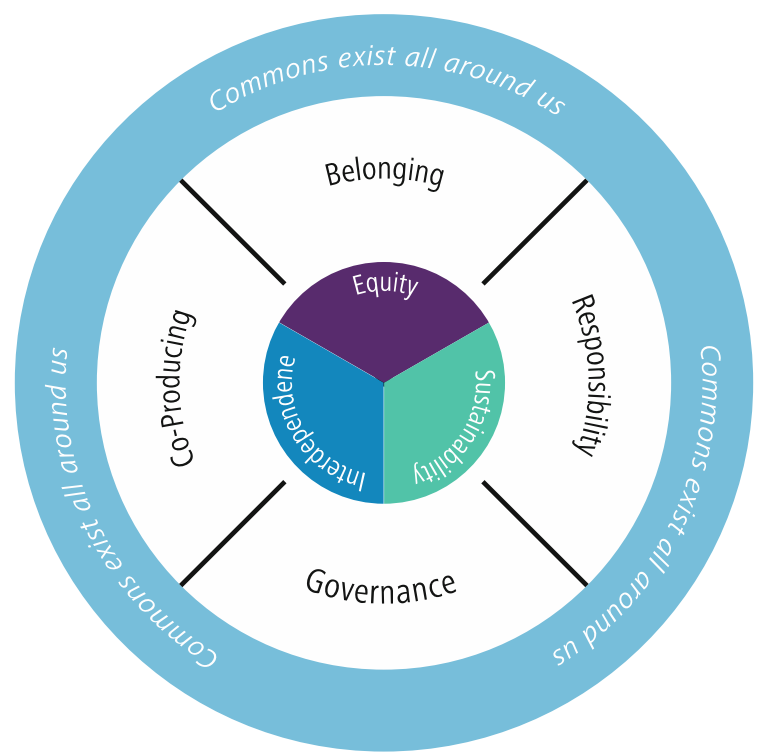

Fig. 4.2 The Commons Framework. Source Based on On the Commons (2012: 1) 
- Belonging-A more expansive view of belonging fosters broader understandings of what ownership means and new structures for how it works.

- Co-Producing-A spirit of common purpose lets us realize that abundance, not scarcity, prevails when we invite wider participation in our endeavors (On the Commons 2012).

The outer ring expresses the general notion that all wealth is the result of our heritage and collaboration and therefore a common outcome. The emphasis is on acknowledging the abundance of many resources instead of declaring their scarcity as the norm. The premise that there can be 'enough' of something is also introduced. The introduction to the commoning book of essays gives plenty of numbers that show how much 'overwealth' or 'Überfluss' there is in the world and that the unsustainable outcomes of today are not created by scarcity but by unsound patterns of production, distribution, and consumption. Change, once again, is less a question of better physical technologies than one of improved processes and systems with their psychological, sociocultural and institutional path dependencies.

In this context, commoning approaches take a very critical stance toward the organizational logic of markets. To them the profit motive and the individualistic competition processes discussed in Chap. 3 are core drivers of unsustainable solutions. At the center of this critique is the ongoing enclosure of natural resources, and therefore the ballooning creation of private goods out of the plenty of the Earth's resources. This creates and perpetuates the notion of scarcity that undergirds economic thinking as a foundational law. Instead, the idea is to align human systems of production and consumption with nature's reproductive laws so that there can be enough for all now and in the future. The aim is to reduce dependence on non-renewables to the minimum and ensure that the use of renewable resources is attuned to their natural circuits of replenishment. As a consequence, rivalry over resource access is significantly reduced.

This view is perfectly in line with what I had dubbed the radically different purpose of 'recoupling.' Relational qualities like sharing and the notion of sufficient or 'enough' output are frequently discussed in this community. Both are, of course, absent from the mainstream economic paradigm but very much the backbone of the imaginary of a safe and just development corridor that is captured in the sustainable development doughnut (Fig. 3.6). Also, the prime question (calculus) behind decision-making and thus the imaginary of the system is not set up around exchange value (what can be sold and bought) but use value (what do I/we need to live well) (Helfrich 2012: 36).

When researching criticism of this approach, I mostly found complaints that it would not be sufficiently critical of structures of domination and would not work strongly enough toward redistribution of wealth, instead inspiring self-defense strategies that remain eternally at niche level. The design principles do seem to suggest a cap on size in order to ensure their proper functioning. Ostrom and colleagues found that the mainstream assumptions of non-cooperation and egoistic strategies tend to emerge in settings where individuals do not know each other, do not communicate effectively, and thus cannot develop agreements, norms, and 
sanctions (ibid.: 419). Processes of globalization, commodification, financialization and also computation have led to the situation in which these settings have become the default organizing structure of our economic systems.

But this cannot count as a criticism of the concept as such if one embraces the idea that human-made productive institutions can and should change if they hamper the alignment of human need satisfaction with respectful and successful resource governance. Commoning is an ideal for processes of contextually fitted governing solutions and thus cannot be benchmarked with reference to the standard organizational appearances of today that, one might want to remind the critics, are definitely not sustainable. Something different will emerge. Given the increasing attention to the concept - as well as the abuse of it for solutions that do not adhere to the principles outlined here - only history can reveal how much of this radical imaginary will be embedded in the transformed systems.

\subsection{Summary: System Innovations for Sustainability by Double-Decoupling}

The goal of this empirical assessment was to track which foundational ideas about human needs and the quality of nature one can find among various initiatives that explicitly reject the mainstream economic paradigm of 'good development.' I have been surprised by the degree of similarity between the ideas, missions and principles as they emerged from different disciplines and cultures.

What we can see is a wave of 'repurposing' differently sized and shaped systems and their institutional design with the radical imaginary that productive processes can be 'recoupled' with human needs and nature's laws. The Economy for the Common Good starts by turning the purpose of business outputs from private profit accumulation toward serving the socio-ecological and economic systems around them. Transition Towns originally started with the redefinition of the purpose of energy systems - from providing cheap and limitless amounts of energy to generating long-term resilient and sustainable systems. GNH is couched in long-standing cultural and religious traditions whose basic idea of what human happiness is marks a paradigm shift not so much for Bhutan but for the Western world and the dominant development paradigm with respect to the purpose of governmentturning away from ensuring private property and limitless consumption possibilities toward building circumstances in which all members of the community feel confident of leading their lives successfully. The Commoning movement, on the other hand, starts by turning the purpose of institutional design away from controlling selfish, unchanging competitors into one that seeks to enable people and communities to bring out the best in themselves.

None of these initiatives claim that they already represent sustainable development in practice. But all of them have a clearly defined beyond-growth purpose that properly integrates rather than subjugates social and ecological dimensions of 
development. These are spelled out, not only in quantitative key performance indicators, but also in qualitative details. These numbers, heuristics and principles change the reference frameworks against which performance and proposed solutions are judged. In effect, the strategic smaller steps amount to what I have called double-decoupling: doing better when it comes to reducing the negative impacts of economic production processes on nature, animals, and humans (first decoupling) and doing well when seeking to establish human need satisfaction strategies that do not depend on exponential growth (second decoupling).

Of course, changing the benchmark changes judgments as to what is promising or acceptable. In the newspapers we usually read that 'productivity,' 'competitiveness,' and 'value creation' need to be constantly increased. But these are empty container terms that can be filled with very different interpretations: what is the benchmark against which I am productive or competitive and create value? One where I am doing the least harm to ecological systems and contribute most to human need satisfaction - or one where my production costs and therefore market prices are as low as possible and my share prices go up? The latter usually means I seek to not account for my environmental damages and push the costs of labor per produced unit as low as possible. These strategies are not very aligned with the purpose of integrating environmental and social concerns with economic ones. Still, externalization is rational if my benchmarks are standards and measures counting an endlessly growing amount of monetary quantifications that are blind to uneconomic real world effects.

The same holds true for politicians. One important economic tool in political decision-making is cost-benefit analysis. In the context of the SDGs, for example, the Copenhagen Consensus Centre, an economic think tank in Denmark, has put forward a cost-benefit analysis of which of the proposed goals will "do the most social good" relative to their costs. They grouped the goals into the categories 'phenomenal,' 'good,' 'fair,' 'poor,' and "not enough knowledge." They claimed to identify the goals in which the money spent would save most lives. This sounds like a great idea. Yet, the analytical tool and mainstream economic mind-set they use is totally inept for transformational strategies. Overturning deeply embedded path dependencies will always produce higher transaction costs, at least in the short term. And what comes across as objective number-crunching entails massive ethical decisions and weighting. Luckily, in this case, key aims were made explicit. So the goal of "achiev[ing] full and productive employment for all" was ranked as 'poor' because "some unemployment is necessary for efficient labor markets" (Copenhagen Consensus Center 2014: 1).

This may be true under current market structures. But it falls short of any ambition for transformational change that might ask why we accept an economic system that necessarily renders some people superfluous. Especially since unemployment can lead to death in countries without social welfare, and is the most important depressor on well-being and quality of life in rich countries. I am not saying that such reasoning is necessarily unethical or wrong. I am saying that unless we pull such assumptions and value judgments out into the light from behind the 'economic evidence' and its key performance indicators, we should not be surprised 
by the solutions that 'economic evidence' supports. In order to achieve deliberative processes of transformation toward sustainable economies and dignified lives, we need to make transparent what has found recognition as cost and benefit, value, utility, or capital, and so on.

The pioneers reviewed above hold assumptions and ideas about humans, their needs and relationships as well as the natural settings in which they operate that are very different from the Homo economicus and natural capital of mainstream economics. They see human behavior and needs as falling more in line with the ontology of reflexive transformation research discussed in Chap. 2 and the criticism of mainstream economics presented in Chap. 3.

None of the pioneering examples subscribe to the three-pillar icon for sustainable development but instead to one of embedded systems (see Fig. 3.4). It is not about dividing the world into pieces and freely moving them around until the balance sheets are optimized. Instead, each element will look and behave differently according to the context in which it happens to sit, and this context will change if parts are removed.

None of the movements accepts the quantifying and monetizing lens as having universal applicability. Market prices are viewed as historically grown institutional set ups with as many distortions, power relations and socializing effects as public institutions. Understanding these is a prerequisite for the determination of which productive relations, goods, and services are best governed by financialized mind-sets and institutions, and which are not.

None of the initiatives subscribe to the idea that maximizing growth forever by accumulating monetized value is a good or even feasible idea. Growth is one of several possible means of securing human happiness and well-being. Its pursuit through the creation of much disutility for many people and by overshooting Planetary Boundaries does not deserve the label 'successful development.'

None of the pioneers ascribe to the idea that comparing and ranking monetary value expressions can provide suitable indications as to what is really happening. All insist on qualitative and physical measures for what is going on in the real world of resources and relations. Instead of pushing a cost-benefit lens onto everything, they seek to understand and find governance and incentive solutions suitable to the actual problem and the relationships in place.

Comparing these respective repurposing decisions for business, communities, governments and civil society initiatives we see a lot of similarities with Sachs' 4 D's of sufficiency as introduced in Chap. 3: deglobalizing and decelerating processes that do not allow for sustainable, resilient and social ways of creating output and solving dilemmas, decommodifying beings and relationships whose primary reason for existence is not that they should be sold in a market, and decluttering the narratives of the future by shedding the dogma that what is here today can never be enough.

For me, such differentiated approaches qualify as trailblazing experiments on how a new, properly integrated sustainability paradigm could be lived in practice. All of them are continuously confronted with creating something new and different while being surrounded and connected with the strong path dependencies of 
overarching and neighboring systems operating along the old ways. In such conditions, radical incremental transformation strategies are more promising than too fast or too drastic changes that would likely cause the old systems to push back or the new parts to be separated off.

Yet, the new purpose of true system innovations should never be left out of sight. As the Global Scenario Group aptly summarizes: "the curve of development must be bent twice. A radical revision of technological means begins the transition. A reconsideration of human goals completes it" Raskin et al. 2002: 95).

So we do not instantly have to set up new businesses, transition our towns or establish new indicators. The second bending requires engagement in what the Germans call 'Deutungshoheit,' which essentially means that we can start exposing the flawed assumptions on which present solutions and plans are built. Work on the reconsideration of humanity's goals or the upset of the human self-image, as the Brundtland Commission foresaw it, remains an open opportunity for all of us, every day.

Where exactly it will lead in the end no one knows. But we do know that the old development model will not lead to sustainability. The final chapter ties key insights of this book together in an attempt to support the clarity, creativity, courage, trust and persistence that radical incremental transformation work requires.

Open Access This chapter is distributed under the terms of the Creative Commons Attribution 4.0 International License (http://creativecommons.org/licenses/by/4.0/), which permits use, duplication, adaptation, distribution and reproduction in any medium or format, as long as you give appropriate credit to the original author(s) and the source, provide a link to the Creative Commons license and indicate if changes were made.

The images or other third party material in this chapter are included in the work's Creative Commons license, unless indicated otherwise in the credit line; if such material is not included in the work's Creative Commons license and the respective action is not permitted by statutory regulation, users will need to obtain permission from the license holder to duplicate, adapt or reproduce the material. 